\title{
ОПЫТ РЕГИОНОВ
}

\section{EXPERIENCE OF REGIONS}

\author{
DOI: 10.12731/2070-7568-2021-10-2-99-119 \\ УДК 657
}

\section{ПРОБЛЕМЫ КАДРОВОГО \\ ПЛАНИРОВАНИЯ В РОССИЙСКИХ КОМПАНИЯХ И ИНСТРУМЕНТЫ ИХ УСТРАНЕНИЯ}

\section{Демидова Е.B.}

Автор статьи исходит из того, что кадровое планирование играет решаюшую роль в реализачии стратегии кадровой политики предприятия, способствует ее воплощению через соответствуюшие мероприятия. Комплектование современными кадрами всех подразделений предприятия невозможно без четкого планирования персонала, которое согласуется с производственными, финансовыми планами, планами научно-исследовательских работ и другими планами предприятия.

В силу того, что система планирования на предприятии включает в себя системную работу по разработке планов - стратегического плана, долговременного плана, текущих и оперативных планов, то особое внимание следует уделить стратегическому плану, который являясь основополагающиим, определяет главные цели предприятия на 10-15 лет вперед, нацелен на долговременное решение вопросов стратегии предприятия. В отличие от него, текущее планирование увязывает все направления деятельности предприятия и работу функциональных служб предприятия, в том числе и службу управления персоналом, однако не является определяющим в перспективном развитии бизнеса.

Практические работники отмечают, что тенденцией развития бизнеса последнего времени стало признание и понимание факта взаимосвязи эффективности кадрового планирования с эффективностью 
самой организащии, в отличие от устаревших взглядов об исключительно закрытии кадровой потребности данной функичей [16, с. 11].

Актуальность и новизна работы определяется тем, что формирование и совершенствование эффективной системы кадрового планирования как предпосылки поступательного развития предприятия выступает базой для определения дальнейших путей изучения данного института на современном этапе, с экстраполяцией результатов на будущее время. Предложенные рекомендации по развитию кадрового планирования на основе передовых международных кадровых технологий позволят преодолеть недостатки существуюших моделей их функционирования.

Цель - разработка рекомендаций по решению наиболее распространенных вопросов совершенствования кадрового планирования на предприятии с учетом последних тенденџий HR-технологий.

Метод или методология проведения работы: в статье использовались общенаучные методы, а также метод экспертных оценок, метод скорректированной экстраполяции планирования персонала.

Результаты: получена модель развития инструментов кадрового планирования с привязкой к стратегии развития предприятия.

Область применения результатов: полученнье результаты возможно применять на производственных предприятиях и организациях.

Ключевые слова: кадровое планирование; стратегия развития предприятия; кадровые технологии

\section{PROBLEMS OF HUMAN RESOURCES PLANNING IN RUSSIAN COMPANIES AND TOOLS FOR THEIR ELIMINATION}

\section{Demidova E.V.}

The author of the article proceeds from the fact that personnel planning plays a decisive role in the implementation of the strategy of the personnel policy of the enterprise, contributes to its implementation through appropriate measures. Recruiting with modern personnel for 
all departments of the enterprise is impossible without clear planning of personnel, which is consistent with production, financial plans, plans for research and development work and other plans of the enterprise.

Due to the fact that the planning system at the enterprise includes systematic work on the development of plans - a strategic plan, a long-term plan, current and operational plans, special attention should be paid to the strategic plan, which, being fundamental, determines the main goals of the enterprise for 10-15 years forward, is aimed at long-term solution of issues of enterprise strategy. In contrast, current planning links all areas of the enterprise's activities and the work of the functional services of the enterprise, including the personnel management service, but is not decisive in the future development of the business.

Practitioners note that the recent trend in business development has been the recognition and understanding of the fact of the relationship between the effectiveness of personnel planning with the effectiveness of the organization itself, in contrast to the outdated views on exclusively covering the personnel needs with this function [16, p. 11].

The relevance and novelty of the work is determined by the fact that the formation and improvement of an effective personnel planning system as a prerequisite for the progressive development of an enterprise serves as the basis for determining further ways to study this institution at the present stage, with extrapolation of the results for the future. The proposed recommendations for the development of personnel planning based on advanced international personnel technologies will allow overcoming the shortcomings of the existing models of their functioning.

Purpose: To development of recommendations about the solution of the most widespread questions of improvement of human resources planning at the enterprise taking into account recent trends of HR technologies.

Methodology in article is used general scientific methods, and also method of expert evaluations, a method of the corrected workforce planning extrapolation were used.

Results: the model of development of instruments of human resources planning with a binding to strategy of development of the enterprise is received. 
Practical implications: it is possible to apply the received results on production enterprises and the organizations.

Keywords: human resources planning; strategy of development of the enterprise; personnel technologies

Главной целью исследования является формулирование рекомендаций к решению наиболее распространенных вопросов совершенствования кадрового планирования на предприятии с учетом последних тенденций HR-технологий.

Достижение цели возможно только при решении нескольких теоретических задач:

1) проанализировать теоретические основы процесса планирования персонала 2) выяснить кадровые условия стратегического развития предприятия 3) предложить рекомендации по совершенствованию кадрового планирования.

Предметом исследования выступает анализ теоретических подходов и некоторых практических ситуаций по вопросам совершенствования процесса планирования персонала предприятия, для достижения оперативности, высокого качества продукции и экономной деятельности предприятия. Данные факторы предопределили дальнейшие направления выработки методолого-практических рекомендаций, направленных на формирование совершенного кадрового планирования в организации.

Планирование выступает сравнительно новым направлением для отечественной науки управления персоналом. Этим объясняется относительно небольшое число публикаций в данной области. Ограниченность объема настоящей статьи позволяет кратко охарактеризовать такие работы.

Часть авторов, публикующихся по данной тематике, например, М.К. Беляев [3, с. 76], А.П. Бушуева [4, с. 13], А.Я. Кибанов, [14, c. 34] схожим образом исследуют фундаментальные вопросы планирования кадров на предприятии, цель которого - принять и закрепить штат работников в нужном количестве с необходимым качеством. При этом они опираются на классические приемы и методы 
работы с персоналом, общеизвестные из учебно-методической литературы.

Вторая группа исследователей например, А.А. Лобанов, А.П. Егоршин [13, с. 115] изучает преимущественно вопросы наилучшего использования потенциала персонала организации, что предполагает их стремление выявить и предвидеть узкие места, образуемые из потенциальной нехватки либо избытка работников.

Третья когорта, например, Ю.Г. Одегов, М.Г. Лабаджян [20, с. 8] в отличие от предыдущих ученых пытаются обосновать связь между подсистемой кадрового планирования и показателями эффективного развития предприятия в целом, что на наш взгляд, наиболее перспективное направление в разрезе управления персоналом и его эффективности как важной части управленческой системы в целом.

Отметим и некоторых современных авторов, пишущих на смежную тему - повышение эффективности работы персонала используя его потенциал, например о внутреннем краудсорсинге, при котором «компании получают возможность улучшить свою деятельность, вовлечь персонал в процесс изменений, сформировать культуру эффективного взаимодействия всех участников трудовых отношений» [9, с. 44].

При этом указанные методики краудсорсинга носят ограниченный характер применения в области кадрового планирования, поскольку представляют собой «специфическую форму использования человеческих ресурсов предприятия, для решения задач, как правило творческого характера...» $[15$, с. 54].

Не могут полностью использоваться и смежные подходы по оптимизации численности персонала в непроизводственных предприятиях, таких как банки, хотя они и связаны с темой кадрового планирования, но не подходят по специфике производства, на что указывают сами авторы: «сама сущность банковских операций предоставление услуг без создания товара в материально-вещественной форме...» [10, с. 154].

Однако, ни одна из вышеперечисленных групп исследователей не изучает вопросы практического использования международных инновационных способов и приемов кадровой работы в части под- 
системы планирования персонала, что выводит их научные разработки из сферы передовых кадровых технологий и существенно снижает их эффективность в практике деятельности российских производственных предприятий.

В этой связи, настоящее исследование делает попытку устранить данный пробел с предложением комплекса мероприятий по усовершенствованию указанной работы на базе передовых международных кадровых технологий.

С целью внесения ясности в базовые понятия, поясним, что термин «кадровое планирование» синонимичен понятию «планирование потребности в персонале», «планирование персонала» и исходит из информации об имеющихся должностных местах, а так же об их структурно-числовой составляющей на будущий период с учетом улучшения производственного цикла, введения перечня технических и организационных мероприятий, а количество персонала (руководителей, специалистов и служащих) формируется на базе существующей системы управления и работ по её усовершенствованию, штатного расписания, перечня заполнения вакантных должностей.

В литературе существует несколько подходов к определению понятия «кадрового планирования» и «планирования» как обобщающего термина.

Уяснить первое понятие и выдвинуть свое определение невозможно без анализа его родового термина - планирование.

Так, В.М. Гриняк утверждает, что планирование в целом - это «процесс определения совокупности организационно-технических, экономических, финансовых и социальных решений и учета необходимых условий для развития предприятия в настоящее время и в обозримой перспективе» [2, с. 135].

Н.Н. Авакумова, в свою очередь, отмечает, что планирование это «процесс презентации случайностей и способности указать на необходимость организационной интеграции и координации для адекватного реагирования на возникающие случайности» [1, с. 78].

По мнению А.П. Егоршина, планирование - это «процесс разработки и увязки отдельных планов в единую комплексную систему и обеспечения тем самым сбалансированности плановых показателей 
как по видам применяемых ресурсов, так и по срокам выполнения планов» [13, с. 361].

В. В. Чурко считает, «планирование представляет собой инструмент проектирования желаемого будущего и эффективных путей его достижения» [6, с. 58].

Переходя к планированию кадров, заметим, что по мнению В.Р. Веснина целью планирования персонала является «краткосрочное, среднесрочное и долгосрочное определение потребностей в персонале, производимое в неразрывной количественной и качественной связи» $[7$, с. 26].

Е.И. Лунева определяя кадровое планирование указывает на своевременное «обеспечение рабочих мест сотрудниками нужной квалификации с одной стороны, а также предоставление рабочих мест уже принятым работникам, с учетом их трудовых навыков, опыта и профессиональных склонностей» [4, с. 23].

М.К. Беляев в свою очередь кадровое планирование определяет через мероприятия направленные на обеспечение организации такими кадрами, которые способны выполнить как текущие, так и перспективные задачи [3, с. 15].

Так же в литературе под кадровым планированием понимается метод управления человеческими ресурсами, который позволяет согласовывать и уравновешивать интересы работодателей и персонала [8, с. 123].

Общим достоинством приведенных определений выступает направленность на выявление потребности в персонале, однако при этом очевиден и их недостаток в целом, который связан с игнорированием кадрового-управленческой составляющей в этом процессе.

На основе вышеприведенных определений понятий «планирование» и «кадровое планирование» в частности, с учетом их схожих черт и различий, мы считаем целесообразным предложить свое авторское определение: «кадровое планирование - это технология работы с персоналом, цель которой состоит в определении потребностей организации в человеческих ресурсах в различных темпоральных периодах (т.е. краткосрочной и долгосрочной перспективе)». 
Кроме этого, можно выделить такую цель кадрового планирования, как сведение к минимуму потерь, обусловленных несовпадением потенциально формируемых в процессе обучения способностей к труду и личных качеств людей с возможностями их использования при выполнении конкретных видов работ, потенциальной и фактической занятостью.

На базе анализа приведенной в конце статьи литературы по теме исследования, все мероприятия, связанные с планированием персонала, предлагается дифференцировать на 3 ключевых нижеперечисленных стадии.

1) Стадия формулирования планов, то есть конкретная процедура планирования, посредством принятия решения о перспективных целях организации и путях их достижения. Итогом этой стадии выступает система планов.

2) Стадия осуществления запланированных решений. Итогом этой стадии выступают реальные цифры производства на предприятия.

3) Стадия контроля результатов. Итогом этой стадии выступает сопоставление полученных результатов с запланированными цифрами производства, а также формирование предпосылок для изменения производственной деятельности предприятия в необходимом направлении. Независимо что контроль выступает заключающей стадией планирования, ее роль велика, по причине того, что он определяет результативность процесса планирования на производстве.

Таким образом, процесс кадрового планирования является первым этапом общей деятельности предприятия.

Так же можно сказать, что процедура кадрового планирования не обычная совокупность действий по формулированию планов и не процесс, смысл которого, что 1 событие необходимо произойдет вслед за другим. Процедура затребует хорошего искусства управления и гибкости. В случае, когда некоторые аспекты процедуры не соответствуют сформулированным компанией целям, то последние возможно обойти, что невозможно в процессе. Задействованные в процедуре планирования работники не только реализуют предпи- 
санные им функции, а выполняют их творчески и расположены к корректированию характера действий, в случае если этого потребует реальность. Процедура планирования кадров включает три основных стадии, которые представлены на рисунке 1.

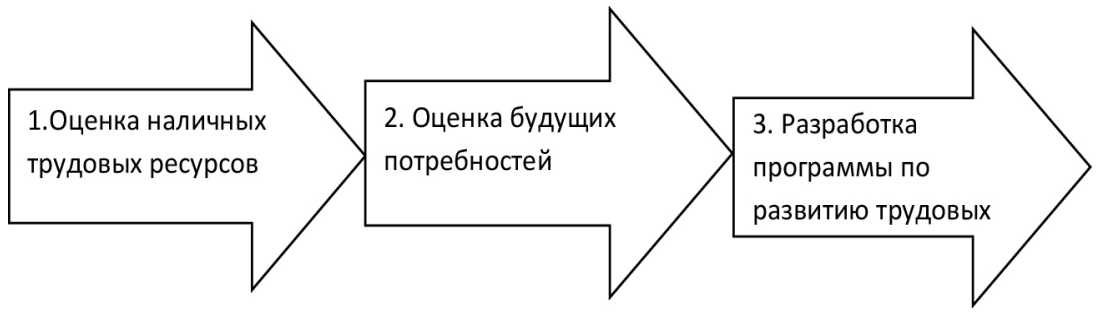

Рис. 1. Планирование персонала предприятия

В общем, процедура планирования заключается в замкнутом цикле по получению прямой (от формулировки стратегического к выделению оперативных планов до воплощения в жизнь с непрерывным контролем) и обратной связью (учет результата исполнения и при необходимости корректирование плана).

Анализ методов кадрового планирования, к которым обычно относят балансовый, нормативный и статистический [14, с. 198], позволяет выделить их недостатки:

- Балансовый метод, к разновидности которого относят штатнономенклатурный, основывается на взаимной увязке ресурсов, которыми располагает организация, и потребностей в них в рамках планового периода. Его недостатком можно выделить отсутствие возможных незапланированных затрат.

- При нормативном методе, в основу плановых заданий на определенный период включаются нормы затрат различных ресурсов на единицу продукции. Проблемы с ним возникают при быстром росте цен на ресурсы, а также разной удельной долей каждого ресурса в единице товара.

- Статистический метод устанавливает зависимость рассматриваемого показателя от других переменных. Он дает сбои в долгосрочной перспективе с изменением структуры затрат. 
При практическом планировании потребности в кадрах (главным образом в практике планирования некоторых действующих российских предприятий, например таких как ОАО «Майсклес» (Кировская область), ООО «Флора» (Хабаровский край), ООО «Смена» (Красноярский край) широко используются такие методы как штатно-номенклатурный и метод определения потребности в персонале по насыщенности.

Касаясь штатно-номенклатурного метода, то его база определена штатным расписанием и организационном плане. Штатное расписание фиксирует взаимосвязь между кадровой нуждаемостью по качественно-количественному отношению с объемом производства, выполняемого организацией. В штатном расписании определена общая структура, наименования и общий перечень должностей (номенклатура должностей), и их количество по разным категориям. Эти рабочие места должны быть заполнены работниками для исполнения плановых управленческих работ и деятельности других видов.

Штатное расписание по существу есть специфическая разновидность плана по персоналу. Этот план помогает по структурно определять необходимость в определенных категориях сотрудников. Выявленные незанятые штатные позиции непосредственно входят в кадровую нуждаемость. Помимо этого, на основе штатного расписания допустимо посредством методики опроса экспертов, а также экстраполяции разработать плановую модель качественно-количественной нуждаемости в работниках, затребованных для производства дополнительного объема работ. При данном случае вносят дополнения в текущее кадровое (штатное) расписание.

Штатно-номенклатурный способ очень хорошо применять в планировании в условиях стабильного объема производства. Однако этот метод базируется на определенных предыдущих нормах нагрузки на работника, которые возможно устарели. В этой связи его применение сопровождается критическим анализом и уточнением таких норм.

Штатное расписание других предприятий используется в методе аналогий. Он применяется в основном при создании новых предприятий или подразделений в деревообрабатывающей отрас- 
ли, когда нет возможностей (средств, времени) использовать другие, более точные и дорогостоящие методы планирования или при нужде в создании чернового варианта новой орг.структуры. Метод аналогий, как и метод бенчмаркинга, использует примеры организации труда аналогичных, по возможности лучших предприятий для нужд собственного предприятия, в данном случае используется их штатное расписание. Этот метод, применяемый творчески, с учетом особенностей собственного предприятия, позволяет достаточно быстро определить примерную потребность в кадрах и создать проект штатного расписания, которое затем может уточняться с помощью других методов планирования персонала.

Повысить точность планирования, основанного на штатном расписании, помогает метод определения потребности в персонале по насыщенности. Особенно целесообразно его применение при отсутствии детальной информации по потребностям организации в определенных категориях работников. Сущность метода заключается в фиксации экспертом коэффициентов насыщенности сотрудниками разных категорий, которые считаются сбалансированным для предприятия в указанных условиях. Данный показатель показывает удельное отношение числа определенной группы сотрудников к составу персонала в целом, объемам производства, размеру базового капитала. С целью повысить точность планирования возможно применить показатели, задействуемые иными схожими компаниями, либо взять средние значения по направлению.

Комплексное решение дают многофакторные электронные табличные модели, представляющие комплекты расчетных формул, позволяющих единовременно использовать экстраполяцию, экспертные оценки, включая сведения об изменении параметров, воздействующих на нуждаемость организации в персонале. Препятствует применению данного подхода отсутствие профессиональных качеств для задействования.

Таким образом, разработка плана по персоналу состоит из процесса формулирования цели и мер по загрузке организации сбалансированным персоналом по качеству и количеству. Назначение 
планирования потребностей в персонале заключается в прогнозировании возможных изменений персонала, определение необходимой численности, состава и структуры персонала, а также путей, способов и форм обеспечения организации персоналом и его эффективного использования, определении мероприятий, способствующих адаптации человеческих ресурсов к изменениям ситуации.

Проведенный анализ научных публикаций [8-15] и собственных исследований в области планирования персонала на российских предприятиях (например, ОАО «Майсклес», ООО «Флора», ООО «Смена») выявил следующие наиболее распространенные проблемы кадрового планирования:

а) отсутствует спецификация должностей;

б) отсутствует система оценки наставников;

в) отсутствует оценка качества обучения сотрудников;

г) неэффективность процесса подготовки руководителей внутри организации;

д) отсутствует мониторинг причин текучести персонала и резервистов.

е) отсутствие плановых отделов, неучастие среднего управленческого персонала в процесс планирования.

Как следствие данных проблем, несоответствие фактической и плановой численности персонала, невысокий уровень сотрудников, успешно прошедших испытательный срок, неудовлетворенность персонала работой на предприятии, несоответствие фактической и плановой численности обученных сотрудников, высокий уровень текучести персонала и резервистов.

Тенденции в работе многих отечественных предприятий показывают, что участие управленческого персонала среднего звена в процесс планирования очень низкая, на многих отсутствуют плановые отделы. Исходя из вышесказанного, можно сделать вывод, что главной причиной данной проблемы является отсутствие четких требований к результатам работы плановых отделов, отсутствие контроля над управленческой деятельностью. Сложившаяся ситуация требует более серьезного отношения руководителя, к подготовке и 
переподготовке своих кадров, плановых работников, владеющих основами рыночного планирования.

На основании проведенного исследования и выявленных проблем можно сформулировать следующие рекомендации по кадровому планированию на производственном предприятии.

Во-первых, необходимо применять диджитализацию, то есть трансформировать бизнес-процессы и кадровое планирование на основе современных технологий. В идеале это: интерактивные корпоративные порталы, подбор персонала через социальные сети, HR-аналитика, электронное обучение. Как минимум, на большинстве отечественных предприятий рекомендуется создать общую программную HR-систему автоматизированных сбора, обработки и учета информации, в частности, сбора и учета кадровой информации, информации сотрудников финансово-экономического блока, сотрудников производственного блока, сотрудников блока партнерских продаж. Доступ к данной системе обеспечить всем заинтересованным лицам - работникам предприятия, для работы которых нужна данная информация, с правом ее использования для целей деятельности, но без права изменения ее исходных данных сотрудниками других отделов (например, сотрудник маркетингового отдела не имеет право изменить информацию в системе о кадрах количестве, табеле учета рабочего времени и т.д., но имеет право изменить исходную информацию по маркетинговой части).

Посредством общей программной системы автоматизированной обработки, учета и сбора информации, которая устанавливается на персональные компьютеры работников предприятия, обеспечивается высокая скорость и легкость движения информации, улучшаются горизонтальные управленческие связи на предприятии, способствующие выработке показателей нуждаемости в кадрах и потребности в совершенствовании существующих.

Во-вторых, нужно активировать кадровую подсистему стратегического развития предприятия через неформальные управленческие связи. Для этого рекомендуется активно проводить семинары, тренинги, совещания, собрания, использовать возможности краудсор- 
синга $[9,15]$. Именно инновационный подход кадровой работы - краудсорсинг позволяет руководителям высокоэффективно отказаться от использования шаблонных методов решения задач, активно использовать творческую инициативу рядовых сотрудников предприятия. Способом реализации является также проведение собраний («разбор полётов») для выявления проблем в управлении, с целью поиска оптимального решения общими усилиями. Задействовать работников финансово блока, менеджеров, секретаря (офис-менеджера), бригадиров. Периодичность проведения - 1 раз в неделю. Проведение внутриорганизационных семинаров, тренингов, собраний, совещаний не требует затрат финансовых затрат. Тем не менее, внедрение на практике предложенной рекомендации будет способствовать улучшению микроклимата в коллективе, сплочению коллектива, повышению конкурентоспособности предприятия на рынке, повышению рентабельности и прибыльности его деятельности.

В-третьих, важно повысить эффективность кадрового планирования через применение «игровых технологий». Гейминговый подход способен успешно применяться для подбора-отбора персонала (через собеседования), в кадровой адаптации, повышения квалификации, стимулировании и достижения обратной связи. Актуальность этот способ получил по причине выхода на рынок персонала молодых кадров, которые характеризуются своей неотрывностью от компьютерных технологий и информационной перегрузкой. Традиционные кадровые схемы работы с такими людьми не работают. На помощь приходит геймификация как метод работы с персоналом [22, c. 125]. Сущностью подхода является введение в рутинный рабочий процесс элементов игры, в том числе посредством компьютерных технологий. Это повышает мотивацию и вовлеченность сотрудников, усиливает горизонтальное взаимодействие. Базовые принципы геймингового подхода, через социальные взаимодействия, эстетики, эмоциональной вовлеченности, сюжетности, достигают удержание внимания и сохраняют интерес персонала. Многочисленные исследования показали, что данный подход более эффективен в сравнении с наставничеством, лекциями и книгами для молодого персонала [16, 18]. 
В-четвертых, важно задействовать концепцию планирования ценности человеческого ресурса как основы стратегического развития фирмы. Социальная ответственность - отличный способ усилить HR-бренд и привлечь ценные кадры. По итогам 2020 года увеличилось число российских компаний, предлагающих различные программы заботы. В числе наиболее популярных программ - полисы страхования ДМС (особенно ценится стоматологическая страховка), предоставление абонементов в фитнес-центр/бассейн, программы анонимной психологической помощи.

В-пятых, с целью повысить вовлеченность управленческого персонала среднего звена в процесс планирования и развития неформальных управленческих связей рекомендуется регулярно и систематически повышать квалификацию персонала, путем посещения сотрудниками (бухгалтерами, экономистами, менеджерами, сотрудниками отдела кадров) различных семинаров, связанных сферой их деятельности и деятельности предприятия, курсов повышения квалификации (для бригадиров обучающие тренинги и семинары проводятся на предприятии постоянно сотрудниками предприятия в рамках их должностных обязанностей).

В-шестых, для устранения недостатков кадрового планирования в части адаптации новых сотрудников предлагается внедрить систему управления процессами адаптации новых сотрудников как одного из его инновационных направлений деятельности. Для этого могут быть применены такие инструменты как: введение адаптационного периода для новых сотрудников; разработка планов введения в должность; разбивка штата по категориям с целью применения более подходящих для них способов адаптации. Данная инновация будет являться улучшающей, поскольку на предприятиях обычно имеются некоторые разрозненные элементы системы адаптации.

Так, в нескольких организациях (например, ОАО «Майсклес», ООО «Флора», ООО «Смена») было выявлено, что стратегическому развитию предприятия мешает отсутствие адаптационного периода сотрудников. Во многих из них практически нет документов оперативного управления, таких как адаптационная программа; планы введения в должности новых сотрудников носят формальный характер, а психофизиологическая адаптация имеет низкий уровень. 
Помимо перечисленного, отсутствует дифференциация персонала по категориям. В связи с этим не разработанность данной системы является негативным моментом и приводит к снижению мотивации работников, повышению тревожности, ухудшению качества труда вплоть до игнорирования своих обязанностей и увольнению.

В-седьмых, повышению эффективности планирования персонала способствует практическое использование инновационных способов кадровой работы: тестирование новых сотрудников; книга сотрудника (корпоративная брошюра); адаптационный лист (включающий задачи на испытательный срок, мероприятия по адаптации; перечень заданий к исполнению; результат выполнения); вводная инструкция о правилах учреждения; индивидуальная программа обучения и стажировки; первоначальное ознакомление сотрудника с общими сведениями об организации; процедура наставничества.

По итогам проведенное исследование показало наличие определенных проблем в процедурах кадрового планирования на отечественных предприятиях, а сформулированная модель мероприятий призвана повысить эффективность работы некоторых элементов кадровой подсистемы производственного предприятия.

При этом проведенный анализ показал, что актуальным назначением кадрового планирования выступает не столько решение текущих вопросов обеспечения кадрами, сколько прогнозирование будущих изменений внешней и внутренней среды предприятия, с целью определить оптимальный состав кадров и способы его обеспечения для этих новых условий.

Одновременно нельзя забывать о взаимосвязи между кадровым планированием и стратегией развития предприятия, которая выражается в разработке кадровой политики, кадровых целях и задачах, мероприятиях по ее реализации.

Поэтому недостаточное внимание руководства к эффективности процедур кадрового планирования на отечественных предприятиях снижает как результативность работы предприятия на внешнем рынке, так и ухудшает внутренние бизнес-процессы, в том числе отражается на удовлетворенности персонала, влечет снижение мотивации и производительности труда. 


\section{Список литературы}

1. Бабич Т.Н. Прогнозирование и планирование в условиях рынка: Учебное пособие / Т.Н. Бабич, И.А. Козьева, Ю.В. Вертакова, Э.Н. Кузьбожев. М.: НИЦ ИНФРА-М, 2013. 336 с.

2. Бабук И.М. Экономика предприятия / И.М. Бабук, Т.А. Сахнович, В.М. Гриняк. М.: ИНФА-М, 2015. 312 с.

3. Беляев М.К. Управление персоналом на предприятии. Волгоград: ВолгГАСА, 2005. 357c.

4. Богдан Н.Н. Основы кадровой политики и кадрового планирования: учеб. пособие / Н.Н. Богдан, И.П. Бушуева, Лунева Е.И; СибАГС. Новосибирск: Изд-во СибАГС, 2013. 103 с.

5. Большая советская энциклопедия : в 30 т. / гл. ред. А.М. Прохоров. М.: Сов. энцикл., 1970-1981. 30 т.

6. Великая Е.Г., Чурко В.В. Индикаторы оценки эффективности организации // Балтийский гуманитарный журнал. 2014. № 2. С. 57-61. https://bg-mag.ru/wp-content/uploads/2021/01/BGZ-2014-27-1.pdf

7. Веснин В.Р. Управление персоналом. Теория и практика. Электронная книга. КноРус, 2015. 360 с.

8. Вырупаева Т.В. Планирование потребности в кадрах // Менеджмент в России и за рубежом. 2016. № 4. С. 122-126.

9. Гиниева С.Б., Долженко Р.А. Внутренний краудсорсинг как инструмент вовлечения персонала // Управленец. 2016. № 3. С. 36-46. http:// upravlenets.usue.ru/ru/-2016/342

10. Долженко Р.А. Вопросы оптимизации численности банковского персонала // Экономика. Бизнес. Банки. 2017. № 2. С. 125-135. http:// rimuniver.ru/wp-content/uploads/2017/09/\%D0\%94\%D0\%BE\%D0\%B B $\%$ D0\%B6\%D0\%B5\%D0\%BD $\%$ D0\%BA\%D0\%BE.pdf

11. Долженко Р.А. Удовлетворенность, лояльность, вовлеченность персонала: уточнение и конкретизация понятий // Вестник алтайского государственного аграрного университета. 2014. № 9. С. 157-162. http://www.asau.ru/vestnik/2014/9/157-162.pdf

12. Долженко Р.А., Сальцев А.А. Новые направления развития наставничества в РФ // Педагогическое образование в России. 2018. № 9. С. 6-12. https://pedobrazovanie.ru/archive/186504/9/novye-napravleniyarazvitiya-nastavnichestva-v-rf 
13.Егоршин А.П. Управление персоналом: Учебник для вузов. 9-е изд., доп. и перераб. Н.Новгород: НИМБ, 2019. 520 с.

14. Кибанов А.Я. Основы управления персоналом. М.: Инфра-М, 2019. 432 c.

15. Котляров И.Д. Место внутреннего краудсорсинга в системе инструментов привлечения персонала для решения нерутинных задач // Менеджмент сегодня. 2016. № 1. С. 54-59. https://grebennikon.ru/ article-6hd6.html

16. Кудряшов В.С. Система кадрового планирования организации // Стратегии бизнеса. 2018. № 7. С. 11-17. https://www.strategybusiness. $\mathrm{ru} /$ jour/article/view/453/390

17. Маркеева А.В. Геймификация как инструмент управления персоналом современной организации // Российское предпринимательство. 2015. T. 16. № 12. C. 1923-1936. https://creativeconomy.ru/lib/9255

18. Маслоу А. Самоактуализация // Психология личности / Под ред. А.А.Пузырея. 2014. 288 с.

19. Мельничук Ю.А. Геймификация как метод стимулирования работы персонала // Материалы Афанасьевских чтений. 2016. С. 100-103.

20. Одегов Ю. Г. Кадровая политика и кадровое планирование / Ю.Г. Одегов, М.Г. Лабаджян. Москва: СИНТЕГ, 2017. 187 с.

21. Пугачёв В.П. Планирование персонала: цели и задачи // Справочник кадровика. 2016. 37 с.

22. Штонда А.С. Геймификация как инструмент успешного управления персоналом // Бизнес-образование в экономике знаний. 2017. № 2. C. 125-131. http://bibs-science.ru/articles/ar377.pdf

23. Castellanos Sara. HR Departments Turn to AI-Enabled Recruiting in Race for Talent // Wall Street Journal . March 14, 2019. https://www. wsj.com/articles/hr-departments-turn-to-ai-enabled-recruiting-in-racefor-talent-11552600459

24. Davies Beth. Competitive advantage with a human dimension: From lifelong learning to lifelong employability // McKinsey Quarterly. February 7, 2019. https://www.mckinsey.com/featured-insights/futureof-work/competitive-advantage-with-a-human-dimension-from-lifelonglearning-to-lifelong-employability 
25. Ramirez Julie Cook. Here are 4 Emerging Trends in HR Tech // Human Resource Executive. March 4, 2019. https://hrexecutive.com/here-are4-emerging-trends-in-hr-tech

26. Scott John. Next Generation Technology-Enhanced Assessment. Cambridge University Press, 2018. 395 p. https://digital.ecopsy.ru/blog/ resources part4

27. Thornton George. Assessment Center Perspectives for Talent Management Strategies. NewYork, Routledge, 2015. 324 p.

\section{References}

1. Babich T.N., Kozeva I.A., Vertakova Yu.V., Kuzbozhev E.N. Prognozirovanie i planirovanie v usloviyakh rynka [Forecasting and planning in market conditions]. M.: INFRA-M, 2013, 336 p.

2. Babuk I.M., Sakhnovich T.A., Grinyak V.M. Ekonomika predpriyatiya [Enterprise Economics]. M.: INFA-M, 2015, 312 p.

3. Belyaev M.K. Upravlenie personalom na predpriyatii [Personnel management at the enterprise]. Volgograd: VolgGASA, 2005, $357 \mathrm{p}$.

4. Bogdan N.N., Bushueva I.P., Luneva E.I Osnovy kadrovoy politiki $i$ kadrovogo planirovaniya [Fundamentals of personnel policy and personnel planning]. Novosibirsk: SibAGS Publ., 2013, 103 p.

5. Bol'shaya sovetskaya entsiklopediya [Great Soviet Encyclopedia]/ ed. A.M. Prokhorov. M.: Sov. entsikl., 1970-1981, vol. 30.

6. Velikaya E.G., Churko V.V. Indikatory otsenki effektivnosti organizatsii [Indicators for assessing the effectiveness of the organization]. Baltiyskiy gumanitarnyy zhurnal [Baltic Humanitarian Journal], 2014, no. 2, pp. 57-61. https://bg-mag.ru/wp-content/uploads/2021/01/BGZ-201427-1.pdf

7. Vesnin V.R. Upravlenie personalom. Teoriya i praktika [Personnel Management. Theory and practice]. Electronic book. KnoRus, 2015, 360 p.

8. Vyrupaeva T.V. Planirovanie potrebnosti v kadrakh [Personnel Needs Planning]. Menedzhment $v$ Rossii i za rubezhom [Management in Russia and Abroad], 2016, no. 4, pp. 122-126.

9. Ginieva S.B., Dolzhenko R.A. Upravlenets, 2016, no. 3, pp. 36-46. http:// upravlenets.usue.ru/ru/-2016/342 
10. Dolzhenko R.A. Ekonomika. Biznes. Banki, 2017, no. 2, pp. 125-135. http:// rimuniver.ru/wp-content/uploads/2017/09/\%D0\%94\%D0\%BE\%D0\%BB $\%$ D0\%B6\%D0\%B5\%D0\%BD $\%$ D0\%BA\%D0\%BE.pdf

11. Dolzhenko R.A. Vestnik altayskogo gosudarstvennogo agrarnogo universiteta, 2014, no. 9, pp. 157-162. http://www.asau.ru/vestnik/2014/9/157-162.pdf

12. Dolzhenko R.A., Sal'tsev A.A. Pedagogicheskoe obrazovanie v Rossii, 2018, no. 9, pp. 6-12. https://pedobrazovanie.ru/archive/186504/9/ novye-napravleniya-razvitiya-nastavnichestva-v-rf

13. Egorshin A.P. Upravlenie personalom: Uchebnik dlya vuzov [Personnel management: Textbook for universities]. N.Novgorod: NIMB, 2019, 520 p.

14. Kibanov A. Ya. Osnovy upravleniya personalom [Fundamentals of personnel management]. M.: Infra-M, 2019, 432 p.

15. Kotlyarov I.D. Menedzhment segodnya, 2016, no. 1, pp. 54-59. https:// grebennikon.ru/article-6hd6.html

16. Kudryashov V.S. Strategii biznesa, 2018, no. 7, pp. 11-17. https://www. strategybusiness.ru/jour/article/view/453/390

17. Markeeva A.V. Rossiyskoe predprinimatel'stvo, 2015, vol. 16, no. 12, pp. 1923-1936. https://creativeconomy.ru/lib/9255

18. Maslou A. Psikhologiya lichnosti [Psychology of personality] / ed. A.A.Puzyrey. 2014, 288 p.

19. Mel'nichuk Yu.A. Geymifikatsiya kak metod stimulirovaniya raboty personala [Gamification as a method of stimulating the work of personnel]. Materialy Afanas 'evskikh chteniy [Materials of Afanasyev's readings], 2016, pp. 100-103.

20. Odegov Yu.G., Labadzhyan M.G. Kadrovaya politika i kadrovoe planirovanie [Personnel policy and personnel planning]. Moscow: SINTEG, 2017, 187 p.

21.Pugachev V.P. Spravochnik kadrovika [Handbook of the personnel officer], 2016, $37 \mathrm{p}$.

22. Shtonda A.S. Biznes-obrazovanie v ekonomike znaniy, 2017, no. 2, pp. 125-131. http://bibs-science.ru/articles/ar377.pdf

23. Castellanos Sara. HR Departments Turn to AI-Enabled Recruiting in Race for Talent // Wall Street Journal . March 14, 2019. https://www. 
wsj.com/articles/hr-departments-turn-to-ai-enabled-recruiting-in-racefor-talent-11552600459

24. Davies Beth. Competitive advantage with a human dimension: From lifelong learning to lifelong employability. McKinsey Quarterly. February 7, 2019. https://www.mckinsey.com/featured-insights/future-of-work/ competitive-advantage-with-a-human-dimension-from-lifelong-learning-to-lifelong-employability

25. Ramirez Julie Cook. Here are 4 Emerging Trends in HR Tech. Human Resource Executive. March 4, 2019. https://hrexecutive.com/here-are4-emerging-trends-in-hr-tech

26. Scott John. Next Generation Technology-Enhanced Assessment. Cambridge University Press, 2018. 395 p. https://digital.ecopsy.ru/blog/resources_part4

27. Thornton George. Assessment Center Perspectives for Talent Management Strategies. NewYork, Routledge, 2015. 324 p.

\section{ДАННЫЕ ОБ АВТОРЕ}

Демидова Елена Викторовна, доцент кафедры «Экономика труда и управления персоналом», кандидат психологических наук Сибирский государственный университет науки и технологий имени академика М. Ф. Решетнёва просп. имени Газеты Красноярский Рабочий, д. 31, г. Красноярск, 660149, Российская Федеращия demidovaev@sibsau.ru

\section{DATA ABOUT THE AUTHOR}

Demidova Elena V., Associate Professor «Labor economics», Candidate of Psychology Sciences

Reshetnev Siberian State University of Science and Technology 31, Krasnoyarskiy Rabochiy, Krasnoyarsk, 660149, Russian Federation

demidovaev@sibsau.ru

SPIN-code: 9163-4377

ORCID: 0000-0002-3836-848X 